http://dx.doi.org/10.1590/0104-1428.1583

\title{
Reciclagem Química do PET Pós-consumo: Caracterização Estrutural do Ácido Tereftálico e Efeito da Hidrólise Alcalina em Baixa Temperatura
}

\author{
Talitha Granja Fonseca, Yeda Medeiros Bastos de Almeida, Glória Maria Vinhas \\ Departamento de Engenharia Química, Universidade Federal de Pernambuco - UFPE
}

\begin{abstract}
Resumo: Devido ao impacto ambiental causado pelo descarte de embalagens PET, a reciclagem desse material tem sido bastante discutida e avaliada. Em particular, a reciclagem química viabiliza a obtenção dos monômeros utilizados na fabricação da resina PET: o etilenoglicol (EG) e o ácido tereftálico (PTA). Por isso, estudos de otimização desse processo são importantes tanto do ponto de vista ambiental, quanto econômico. Neste trabalho foram investigados certos parâmetros que influenciam a reação de despolimerização do PET pós-consumo via hidrólise alcalina, a fim de obter o PTA. Os ensaios foram realizados à temperatura de $70{ }^{\circ} \mathrm{C}$, variando a concentração da solução de hidróxido de sódio e o tempo de reação. Os melhores resultados foram obtidos para concentração de $\mathrm{NaOH} 10,82 \mathrm{~mol} \mathrm{~L}^{-1}$ e tempo de reação de $9 \mathrm{~h}$. Consequentemente, foi possível comprovar a viabilidade do processo, uma vez que as análises por infravermelho e Ressonância Magnética Nuclear confirmaram a obtenção do PTA em todas as reações realizadas.
\end{abstract}

Palavras-chave: Despolimerização, PET, hidrólise alcalina.

\section{Chemical Recycling of Post-consumer PET: Structural Characterization of Terephthalic acid and the Effect of Alkaline Hydrolysis at Low Temperature}

Abstract: Due to the environmental impact caused by PET packaging disposal, this material recycling has been thoroughly discussed and evaluated. In particular, chemical recycling enables achievement of the monomers that are used in PET resin manufacture: ethylene glycol (EG) and terephthalic acid (PTA). Therefore, studies for this process optimization are important from environmental and economic points of view. The present study investigated certain parameters that influence the depolymerization reaction of PET post-consumer via alkaline hydrolysis in order to obtain PTA. Assays were performed at $70^{\circ} \mathrm{C}$ by varying the concentration of sodium hydroxide and the reaction time. The best results were obtained at $10.82 \mathrm{~mol} \mathrm{~L}^{-1} \mathrm{NaOH}$ and $9 \mathrm{~h}$ reaction time. Consequently, it was possible to prove this process viability, once analyses by infrared and nuclear magnetic resonance confirmed that PTA was obtained in all reactions performed.

Keywords: Depolymerizing, PET, alkaline hydrolysis.

\section{Introdução}

O Poli(tereftalato de etileno) (PET) é um dos termoplásticos mais produzidos no mundo, utilizado em fibras têxteis (67\%), embalagens processadas por injeçãosopro (24\%), filmes biorientados $(5 \%)$ e polímeros de engenharia $(4 \%)^{[1]}$. O sucesso da aplicação do PET deve-se a sua excelente tração e resistência ao impacto, resistência química, propriedades de barreira a gases, capacidade de processamento, brilho e estabilidade térmica ${ }^{[2]}$.

No Brasil, somente em 2011, foram consumidas cerca de 515.000 toneladas de resina PET na fabricação de embalagens. Dessa quantidade, $57,1 \%$ foram efetivamente recicladas, o que tornou este país o segundo que mais reciclou PET no mundo, perdendo apenas para o Japão ${ }^{[3]}$. Apesar disso, o descarte das embalagens, principalmente de bebidas carbonatadas, em lixos municipais, é um problema grave, devido à difícil degradação em aterros sanitários e à impossibilidade da compostagem ${ }^{[3]}$. Assim, o processo de reciclagem, não só primária (produtos fora da especificação na indústria), mas também secundária, terciária ou quaternária (produtos descartados após o consumo) é uma alternativa para amenizar o impacto ambiental causado por esse polímero ${ }^{[4]}$.

A reciclagem química ou terciária conduz à total despolimerização do PET aos monômeros, ou parcial aos oligômeros e a outros compostos, e pode ser realizada pelos processos de hidrólise, glicólise, metanólise e aminólise ${ }^{[4]}$. A decomposição via hidrólise, em particular, além de colaborar com o propósito ambiental, também contribui economicamente, pois por meio dela é possível obter etilenoglicol (EG) e, principalmente, ácido tereftálico (PTA) com apenas uma reação ${ }^{[5]}$. A esterificação do PTA com etileno glicol a uma temperatura entre $240^{\circ} \mathrm{C}$ e $260^{\circ} \mathrm{C}$ e uma pressão compreendida entre $300 \mathrm{kPa}$ e $500 \mathrm{kPa}$ é a principal alternativa industrial de síntese da resina $\mathrm{PET}^{[2]}$.

Dentre os processos catalisados por ácidos, bases ou catalisadores neutros, destacam-se aqueles ocorridos

Autor para correspondência: Glória Maria Vinhas, Departamento de Engenharia Química - DEQ, Centro de Tecnologia e Geociências, Universidade Federal de Pernambuco - UFPE, Av. Prof. Artur de Sá, s/n, Cidade Universitária, CEP 50740-521, Recife, PE, Brasil, e-mail: gmvinhas@yahoo.com.br 
em meio alcalino. A ausência de íons hidrogênio para desestabilizar a carbonila é compensada pela presença de um reagente mais nucleofílico, normalmente um hidróxido $\left(\mathrm{OH}^{-}\right)$, ao invés da água. $\mathrm{O}$ cátion da base, mais forte que os poucos íons hidrogênio gerados pela ionização da água, completa a reação ${ }^{[4]}$.

Além do meio reacional, a estrutura e tamanho do PET a ser despolimerizado devem ser bem definidos, pois, abaixo da faixa do ponto de fusão cristalina do PET (entre 255 e $265^{\circ} \mathrm{C}$ ), a hidrólise é claramente uma reação heterogênea, ocorrendo na interface sólido-líquido ${ }^{[6]}$. Assim, quanto maior a área da partícula, maior será o rendimento, e, portanto, partículas de PET em formato de flakes apresentam maior rendimento que partículas em formato de pellets ${ }^{[6]}$.

Vários estudos ${ }^{[1,2,4-7]}$ sobre o processo de despolimerização do PET via hidrólise alcalina tem sido realizados. Entretanto, as metodologias atualmente encontradas na literatura para esta reação são dispendiosas, uma vez que problemas como a penetração de reagentes químicos no interior da matriz de polímero, devido a sua resistência a tais reagentes, e a difícil solubilização dos resíduos de plástico comprometem o rendimento da reação de despolimerização ${ }^{[7]}$. Portanto, o estudo da despolimerização do PET, a fim de otimizar o processo, tem sido destaque nesta área.

Partindo de análises dos trabalhos da literatura ${ }^{[1,2,4-7]}$, que operam apenas com temperaturas maiores ou iguais a $100^{\circ} \mathrm{C}$, nesse trabalho propõe-se empregar uma temperatura de $70{ }^{\circ} \mathrm{C}$, a fim de verificar a possibilidade de otimização do processo. Também foram investigados parâmetros que interferem no rendimento desta reação: a concentração da solução de hidróxido de sódio e o tempo da reação.

A PCAé uma técnica quimiométrica de reconhecimento de padrões, ou seja, utiliza ferramentas matemáticas e estatísticas para explorar os resultados obtidos por meio de análises químicas. Através da redução de dimensões, ela permite detectar padrões ou agrupamento de amostras com características semelhantes, estabelecer quais variáveis são correlacionadas ou redundantes e observar amostras anômalas. A redução da dimensão do espaço de parâmetros é realizada através da transformação da variável original, representando-a em novos eixos. Neste contexto, foi feita uma PCA dos espectros no infravermelho do ácido tereftálico das reações de despolimerização para detectar semelhança química entre as estruturas com o propósito de avaliar a eficiência do processo de despolimerização ${ }^{[8]}$.

\section{Experimental}

\section{Materiais}

Todos os ensaios foram realizados com amostras de PET reciclado em formato de flakes com dimensão inferior a $2,0 \mathrm{~cm}^{2}$, cedido pela recicladora FROMPET, localizada em Jaboatão dos Guararapes-PE. As soluções foram preparadas, utilizando hidróxido de sódio em pérola P.A., marca Fmaia, pureza mínima de 97,0\%, e ácido sulfúrico P.A., marca
Vetec, pureza de 97\%. Além disso, nas filtrações a vácuo, utilizou-se papel de filtro quantitativo, faixa azul, marca Química Moderna.

\section{Métodos}

\section{Reação de despolimerização e determinação do rendimento}

Para cada ensaio, $50 \mathrm{~mL}$ da solução de hidróxido de sódio em diferentes concentrações $(5,18 \mathrm{M}, 8,0 \mathrm{M}$ e 10,82 M) foram colocados num balão de três ou duas bocas em um sistema de aquecimento (recipiente contendo óleo de silicone), agitação magnética e refluxo. Quando a temperatura desejada estava seguramente estabilizada $\left(70 \pm 3{ }^{\circ} \mathrm{C}\right)$, adicionou-se, rapidamente, pela entrada do balão onde era acoplado o termômetro, aproximadamente $1 \mathrm{~g}$ do PET. A partir desse momento, iniciou-se a contagem do tempo de reação.

Ao término do tempo reacional $(3 \mathrm{~h}, 5 \mathrm{~h}, 7 \mathrm{~h} \mathrm{e} 9 \mathrm{~h})$ a mistura heterogênea, contendo etilenoglicol, tereftalato dissódico e resíduos de PET não hidrolisados, foi rapidamente resfriada em banho de gelo, neutralizada com excesso de solução de ácido sulfúrico $10 \% \mathrm{v} / \mathrm{v}$ até $\mathrm{pH}$ zero e colocada sob refrigeração para facilitar a formação dos cristais de PTA. Após uma semana, realizou-se a filtração a vácuo, com lavagem em água. O PTA (insolúvel em água) e os resíduos poliméricos, após secagem, foram pesados. O rendimento de cada ensaio foi calculado através da análise gravimétrica da reação de despolimerização do PET.

\section{Espectroscopia de Ressonância Magnética Nuclear de hidrogênio}

$\mathrm{O}$ espectro de $1 \mathrm{H}$ RMN de cada amostra foi obtido com freqüência de $300 \mathrm{MHz}$, utilizando dimetilssulfóxido deuterado (DMSO-d6) como solvente. Os deslocamentos químicos foram avaliados qualitativamente e os dados tratados utilizando o programa de computador MestRec ${ }^{\circledR}$.

\section{Espectroscopia no Infravermelho (FTIR)}

As análises de espectroscopia no infravermelho (FTIR) foram realizadas no Espectrômetro Spectrum 400 FT-IR/ FT-NIR - Perkin Elmer, com acessório UATR (Reflectância Total Atenuada) e os espectros foram obtidos com resolução de $4 \mathrm{~cm}^{-1}$, empregando-se o total de 16 scans e faixa de 4000 a $400 \mathrm{~cm}^{-1}$.

\section{Análise por componentes principais}

Para análise da PCA foi utilizado o software Unscrambler, versão 9.7. Esse programa constrói uma matriz de dados multivariados, onde cada variável representa um eixo do espaço matemático das características das amostras. São realizadas manipulações algébricas na matriz de covariância das variáveis e novos eixos são calculados, com direção no sentido da maior variância. Esses novos eixos são as componentes principais (PCs). A matriz de dados analisada foram espectros sem pré-processamento das amostras de ácido tereftálico obtidas em 15 reações de despolimerização realizadas pela combinação das variáveis: temperatura $\left(70{ }^{\circ} \mathrm{C}\right.$ ou $\left.100^{\circ} \mathrm{C}\right)$, concentração $(5,18 \mathrm{M}, 6 \mathrm{M}, 8 \mathrm{M}, 10 \mathrm{M}$ e 10,82 M) e tempo reacional ( $3 \mathrm{~h}, 5 \mathrm{~h}, 7 \mathrm{~h}$ e $9 \mathrm{~h}$ ). 


\section{Resultados e Discussões}

Estudo preliminar da despolimerização do PET na forma de flakes e pellets foi realizado pelo grupo, e constatou-se que os maiores rendimentos foram alcançados com o PET na forma de flakes, corroborando com os resultados obtidos por Curti \& Ruvolo Filho ${ }^{[6]}$.

Ao término do tempo reacional de todas as reações de despolimerização realizadas, observou-se uma mistura composta por uma fase líquida e pouco turva, correspondendo ao etilenoglicol com sal tereftalato dissódico (ver Figura 1), e uma fase sólida, composta pelos resíduos de PET não hidrolisado. Ao acidificar a mistura, o sal foi convertido em PTA, insolúvel em água. O fino pó (PTA) obtido depois da filtração foi analisado por infravermelho e Ressonância Magnética Nuclear de Hidrogênio.

A análise da influência dos parâmetros estudados foi feita através dos resultados de rendimento da Tabela $1 \mathrm{e}$ dos gráficos que relacionam tempo de reação e rendimento, mantendo a concentração fixa (Figura 2); e concentração e rendimento, mantendo o tempo de reação fixo (Figura 3).

Na Figura 2a, b e c observa-se que, para concentrações constantes, o rendimento se relaciona linearmente com o tempo de reação, com desvios um pouco maiores para três horas de reação. Isso ocorre, possivelmente, devido ao maior volume de PET não hidrolisado, onde se acumula, inevitavelmente, uma pequena quantidade do pó de PTA. Também é verificado que os maiores rendimentos são obtidos para o maior tempo de reação.

Tabela 1. Resultados de rendimento das reações de despolimerização realizadas a temperatura de $70^{\circ} \mathrm{C}$.

\begin{tabular}{ccccc}
\hline Concentração & \multicolumn{4}{c}{ Rendimento (\%) para cada Tempo de Reação } \\
\cline { 2 - 5 } (M) & 3 horas & $\mathbf{5}$ horas & $\mathbf{7}$ horas & 9 horas \\
\hline 5,18 & 3,85 & 6,97 & 12,76 & 14,6 \\
8 & 14,71 & 30,54 & 38,89 & 50,22 \\
10,82 & 43,77 & 57,14 & 70 & 92,37 \\
\hline
\end{tabular}<smiles>COC(=O)c1ccc(C(=O)OCCC(C)(C)NO)cc1</smiles>

Poli (tereftalato de etileno) (PET)

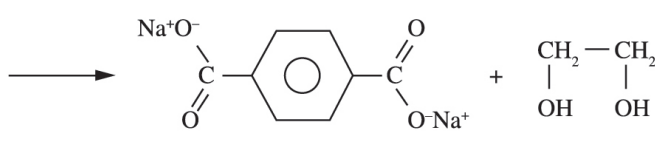

Tereftalato dissódico Etilenoglicol<smiles>[3H][AsH3]</smiles><smiles>O=C(O)c1ccc([N+](=O)O)cc1</smiles>

Ácido tereftálico (PTA)

Figura 1. Esquema da reação de despolimerização do PET via hidrólise alcalina.

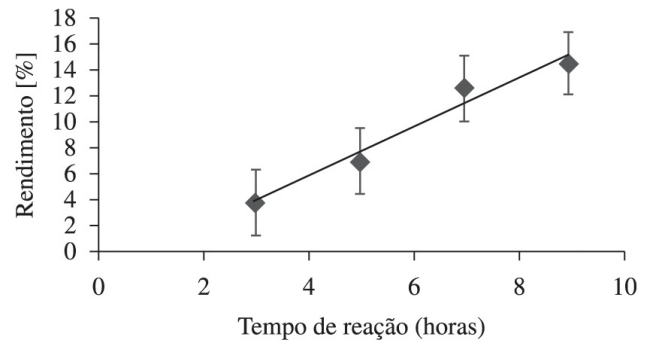

(a)

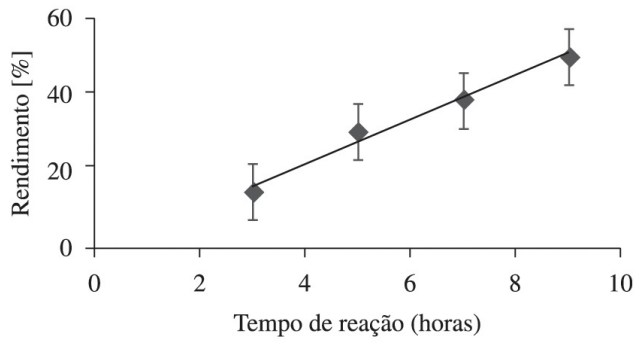

(b)

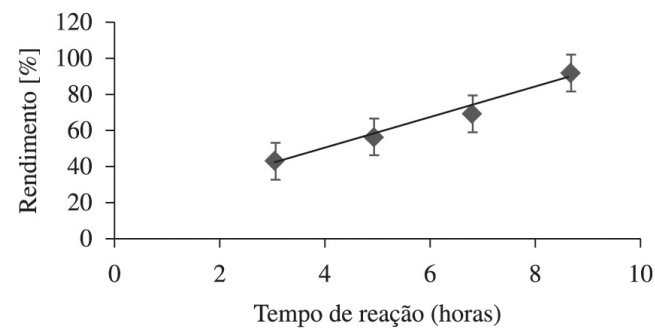

(c)

Figura 2. Resultados de extensão de reação em função do tempo de hidrólise do PET submetido à hidrólise em soluções aquosas de hidróxido de sódio $5,18 \mathrm{M}$ (a), $8 \mathrm{M}$ (b) e $10,82 \mathrm{M}$ (c) a $70{ }^{\circ} \mathrm{C}$. 


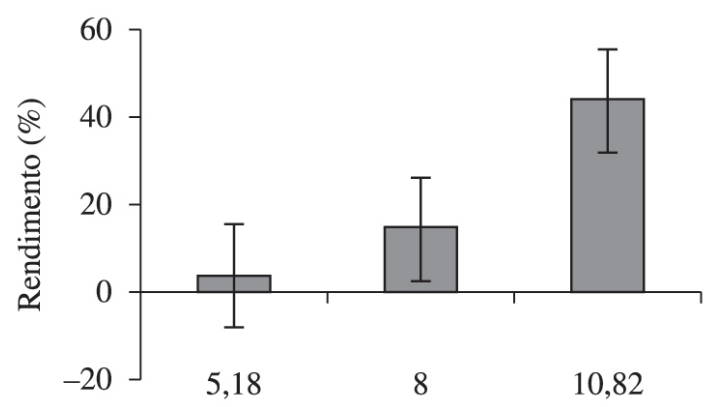

Concentração (M)

(a)

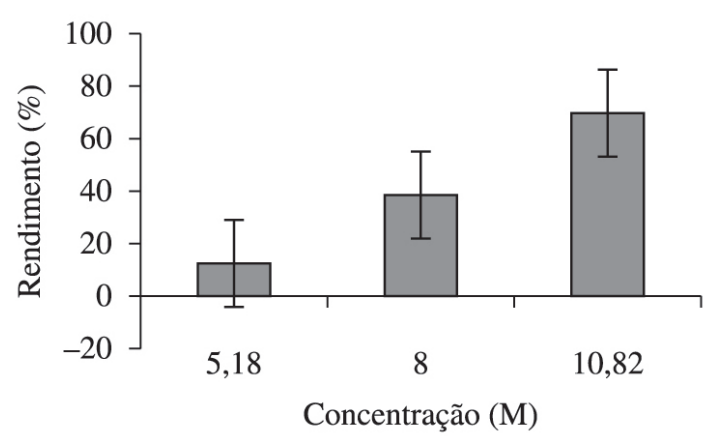

(c)

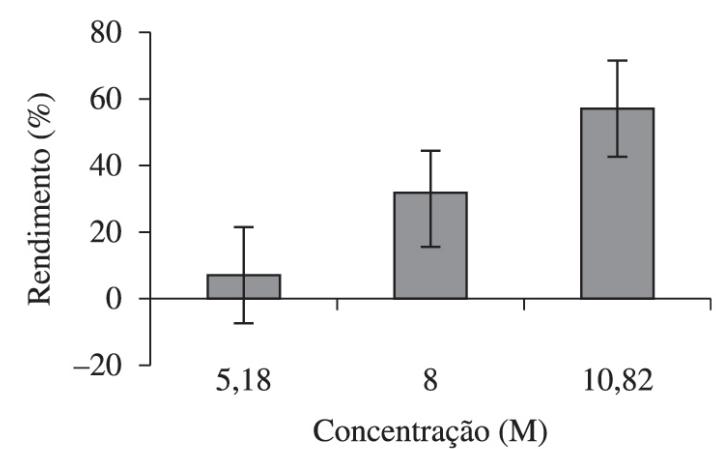

(b)

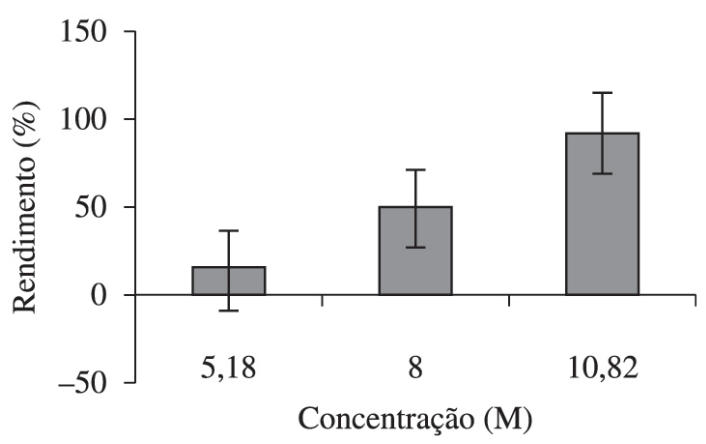

(d)

Figura 3. Resultados de extensão de reação em função da concentração da solução de hidróxido de sódio, utilizada para hidrólise do PET durante 3 horas (a), 5 horas (b), 7 horas (c) e 9 horas (d).

Além disso, a relação entre o rendimento e a concentração da solução de hidróxido de sódio é mostrada na Figura 3a, b, c e d. Apesar de não linear, o rendimento também é diretamente proporcional à concentração de hidróxido de sódio. Para o tempo fixo de 9 horas, foram obtidos os melhores resultados, com destaque para o rendimento de $92,37 \%$ na concentração de 10,82 M.

É importante destacar que a percentagem de PET hidrolisado foi muito próxima à percentagem de PTA formado em todos os ensaios. Assim, a massa de PTA impregnada nos resíduos de PET não hidrolisado foi mínima e, para as reações de maior tempo, foi praticamente nula, já que grande parte do PET foi hidrolisada.

Embora a literatura não apresente estudos dessa reação na temperatura inferiores de $70{ }^{\circ} \mathrm{C}$, resultados observados por Di Souza et al. ${ }^{[4]}$ e por Mancini \& $\operatorname{Zanin}^{[5]}$, que trabalharam a $100{ }^{\circ} \mathrm{C}$, podem ser utilizados para comparação. Com uma média de 6 horas de reação e solução de $\mathrm{NaOH}$ 7,5 M, Mancini \& Zanin $^{[5]}$ obtiveram rendimentos de $95 \%$ em média, enquanto Di Souza et al. ${ }^{[4]}$ conseguiram rendimentos próximos a $100 \%$. Considerando a diferença de temperatura, parâmetro bastante significativo no rendimento da reação, pode-se julgar os resultados obtidos nesse trabalho satisfatórios.

Foi realizada, então, a caracterização do produto obtido nas reações de despolimerização do PET. A
Figura 4 representa o espectro de $1 \mathrm{HRMN}$ do PTA obtido na reação de maior rendimento (concentração de $\mathrm{NaOH}$ igual a 10,82 $\mathrm{M}$ e tempo de reação de 9 h). São verificados o grupo hidroxila de ácido carboxílico e o anel aromático para-substituído. Os deslocamentos químicos $(\delta$, em ppm) para ambos são dados: 13,3 (s, 2H, $\mathrm{OH})$ e 8,04 (s, 4H, H-Ar). A presença de água no ácido tereftálico evidencia a necessidade de aprimoramento no processo de secagem.

Oku et al. ${ }^{[9]}$ caracterizaram por $1 \mathrm{HRMN}$ o PTA obtido na reação de despolimerização do PET na forma de pellets, verificando também a presença da água na amostra do ácido.

O espectro de infravermelho do ácido tereftálico obtido também da reação de despolimerização de maior rendimento encontra-se na Figura 5 em linha cheia, bem como o espectro do PTA comercial, fornecido pela TERPHANE, em linha tracejada. Percebe-se grande similaridade das bandas vibracionais do espectro do PTA comercial com PTA obtido experimentalmente.

Ambos os espectros apresentam uma banda larga entre $3300 \mathrm{~cm}^{-1}$ e $2100 \mathrm{~cm}^{-1}$, atribuída ao estiramento da hidroxila ligada à carbonila do ácido e, provavelmente a água residual. Verifica-se o pico da carbonila em $1670 \mathrm{~cm}^{-1}$ e bandas associadas ao estiramento $\mathrm{C}-\mathrm{OH}$ acoplado com a deformação $\mathrm{O}-\mathrm{H}$, em $1300 \mathrm{~cm}^{-1}$ e $1425 \mathrm{~cm}^{-1}$. Também se observa os picos relacionados ao estiramento $\mathrm{C}=\mathrm{C}$ no 


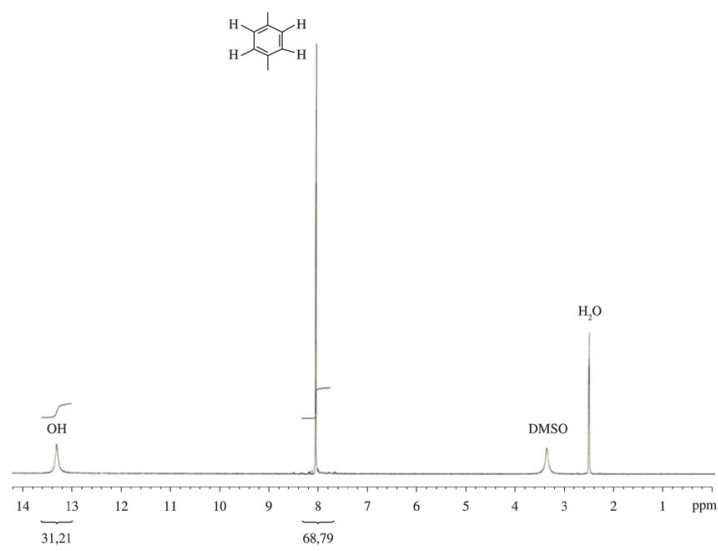

Figura 4. Espectro 1H-RMN do monômero PTA em DMSO-d6.

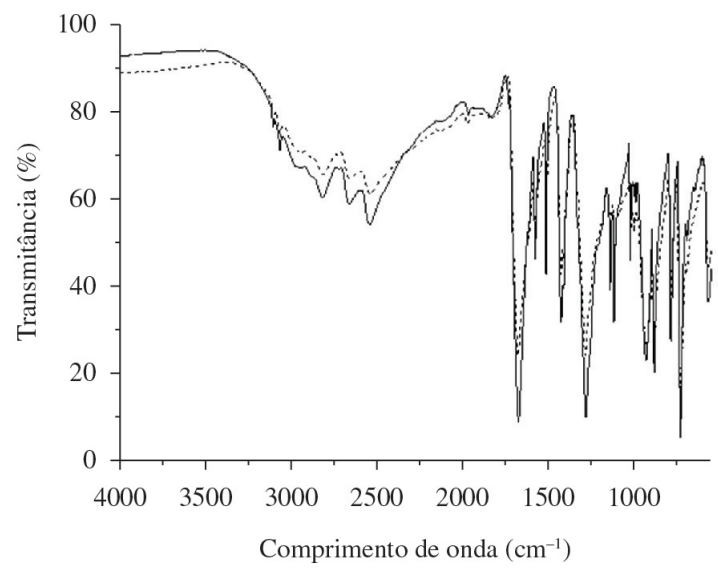

Figura 5. Espectros do PTA obtido na reação de despolimerização com concentração de hidróxido de $10,82 \mathrm{M}$ e tempo de reação de $9 \mathrm{~h}$ (linha cheia) e do PTA comercial (linha tracejada).

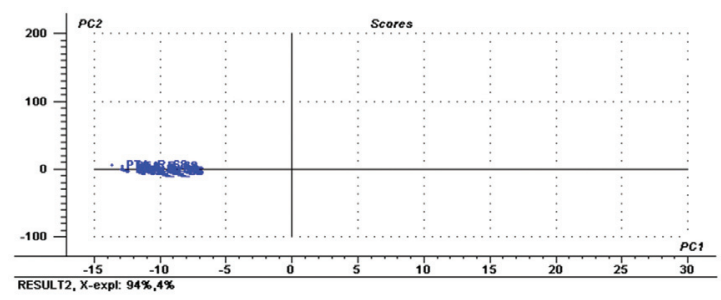

Figura 6. Gráfico de escores para $\mathrm{PC} 1$ versus $\mathrm{PC} 2$ dos espectros sem pré-processamento das amostras de ácido tereftálico.

anel aromático e à deformação da vibração do anel 1,4 dissubstituído, em $1574 \mathrm{~cm}^{-1}$ e $726 \mathrm{~cm}^{-1}$, respectivamente.

A análise por componentes principais (PCA) permite verificar possíveis tendências de classificação das amostras. A partir desta análise, apresentada na Figura 6, percebe-se que há similaridades nas estruturas químicas dos produtos obtidos, já que a PCA classificou somente um grupo de espectros com características semelhantes. Isso mostra a eficiência do processo de despolimerização em diferentes condições reacionais associada à qualidade dos flakes de PET pós-consumo, evidenciando um controle da reciclagem do PET na indústria recicladora FROMPET.

\section{Conclusões}

Com esse trabalho foi possível comprovar a viabilidade da reciclagem química do poli (tereftalato de etileno) a uma temperatura inferior a $100^{\circ} \mathrm{C}$. A concentração da solução de $\mathrm{NaOH}$ e o tempo de reação foram analisados quanto a suas influências na reação. Observou-se que o rendimento depende diretamente desses parâmetros. Portanto, o melhor resultado, $92,37 \%$, foi obtido utilizando a maior concentração de $\mathrm{NaOH}(10,82 \mathrm{M})$ e maior tempo de reação (9 h) na temperatura de $70{ }^{\circ} \mathrm{C}$.

No espectro de 1HRMN do PTA obtido foi confirmada a estrutura do ácido. Através de caracterização de infravermelho foi possível observar semelhança das bandas vibracionais do espectro do ácido tereftálico comercial e do ácido obtido pela reação de despolimerização. A semelhança das bandas vibracionais de todas as reações de despolimerização foi confirmada pela análise de componentes principais, bem como a qualidade dos flakes fornecidos pela indústria FROMPET.

\section{Agradecimentos}

Os autores agradecem ao Laboratório de Combustíveis (LAC) do Departamento de Engenharia Química da Universidade Federal de Pernambuco, pela realização das análises de infravermelho, ao Laboratório de Materiais Poliméricos e Caracterização (LMPC) e ao Programa de Recursos Humanos ANP/PETROBRAS, PRH 28, pelo apoio logístico e financeiro.

\section{Referências Bibliográficas}

1. Romão, W.; Spinacé, M. A. S. \& De Paoli, M. A. - Polímeros, 19, p.121 (2009). http://dx.doi.org/10.1590/S010414282009000200009 .

2. Awaja, F. \& Pavel, D. - Eur. Polym. J., 41, p.1453 (2005). http://dx.doi.org/10.1016/j.eurpolymj.2005.02.005.

3. Compromisso Empresarial para Reciclagem - CEMPRE - "Fichas técnicas: PET", CEMPRE. Disponível em: <http:// www.cempre.org.br/ft_pet.php>. Acesso em: jun. 2013.

4. Di Souza, L. Torres, M. C. M. \& Ruvolo Filho, A. C. Polímeros., 18, p.334 (2008). http://dx.doi.org/10.1590/ S0104-14282008000400013.

5. Mancini, S. D. \& Zanin, M. - Polímeros, 12, p.34 (2002). http:// dx.doi.org/10.1590/S0104-14282002000100016. Curti, P. S. \& Ruvolo Filho, A. C. - Polímeros, 16, p.276 (2006). http:// dx.doi.org/10.1590/S0104-14282006000400006

7. Abdelaal, M. Y.; Sobahi, T. R. \& Makki, M. S. I. - Int. J. Polym. Mater., 57, p.73 (2008). http://dx.doi. org/10.1080/00914030701329080.

8. Adams, M. J. - "Chemometrics in analytical spectroscopy", Springer Verlag, Cambridge (1995).

9. Oku, A.; Hu, L. C. \& Yamada, E. - J. Appl. Polym. Sci., 63, p.595 (1997). http://dx.doi.org/10.1002/(SICI) 1097 4628(19970131)63:5<595:AID-APP7>3.0.CO;2-P.

Enviado: Out. 10, 2013

Reenviado: Mar. 13, 2014

Aceito: Abr. 15, 2014 